\title{
Predietary Counseling in Ketogenic Diet: The 5R Model
}

\author{
Rahul Rosha ${ }^{1}$ Rajiv Singla ${ }^{2}$ Bharti Kalra ${ }^{3}$ \\ ${ }^{1}$ Department of Nutrition, Novique Healthcare, Pune, Maharashtra, India \\ ${ }^{2}$ Department of Endocrinology, Kalpavriksh Healthcare, New Delhi, India \\ ${ }^{3}$ Department of Gynaecology, Bharti Hospital, Karnal, Haryana, India \\ J Soc Health Diab 2018;6:72-74
}

\begin{abstract}
Address for correspondence Bharti Kalra, MD, Department of Gynaecology, Bharti Hospital, Karnal 132001, Haryana, India (e-mail: dr.kalrabharti@gmail.com).
\end{abstract}
Abstract
Keywords
- Atkin's diet
- diabetes
- ketogenic diet
- medical nutrition therapy
- obesity
- weight loss

A major determinant of success while following a ketogenic diet is the counseling that precedes and accompanies the dietary advice. Effective predietary counseling lays a strong foundation upon which successful outcomes can be built. Predietary counseling, an art as well as a science, is best understood through a bio-psychosocial viewpoint. This brief communication shares an alliteratively named model, the $5 R$ rubric. Rapport, realistic realization, reliability, readiness to change, and relationship must be explored and improved during the process of counseling. These five R's remind one to practice continuous, holistic counseling, without forgetting any of the factors that may impact outcomes. Pre-ketodietary counseling is a theranostic intervention, as it helps in both assessment (diagnosis) and improving outcomes (therapeutics).

\section{Introduction}

Ketogenic diet is an important, scientific method of treatment in diabetes and obesity. ${ }^{1}$ Most literature on ketogenic diet relates to its use in epilepsy, and expert guidance on optimizing its weight loss benefit is scarce. ${ }^{2,3}$ One way of ensuring that ketogenic diet is used in a safe and efficient manner is to provide quality counseling. "Keto-counseling," as we term it, is an ongoing process, which begins before institution of the diet, continues throughout the process of dieting and after it as well.

We share a $5 \mathrm{R}$ model (- Table 1 ) to help ketogenic diet care teams ensure that optimal counseling is done prior to starting the therapy. Appropriate predietary counseling ensures correct patient selection, enhanced adherence, and persistence, and thus facilitates maximal therapeutic outcomes.

\section{Biopsychosocial Rubric}

The domains of pre-ketogenic dietary counseling are best understood through a bio-psychosocial prism. ${ }^{4}$ Counseling should be viewed as a theranostic and educative intervention, which aims to diagnose (suitability for ketogenic diet), educate (regarding the diet), and treat (enhance readiness, reliability, and resilience). These aims can easily be fulfilled if one is able to gauge the biomedical, psychological, and social fitness of the individual (-Table 2). Such assessment helps in identifying strengths and limitations, as well as suggesting methods of improving dietary, metabolic, and overall health.

\section{Rapport}

The first step in counseling is relationship building. ${ }^{5}$ Frequent friendly contact helps create a rapport between the person and her/his health care team. Exploratory discussion encourages the individual explore her/his health from a bio-psychosocial perspective. Current health status, current behavior, the need for change, and the reason for change must be analyzed by the person. This process of self-analysis, or self-realization, is promoted by ongoing dialogue with the health care team. Such conversation must be performed in an atmosphere of respect and relaxation. Modes of contact may include face-to-face meetings and telephonic and online conversations.

\section{Realistic Realization}

During predietary counseling, information about the rationale, dos and don'ts, and caveats of the ketogenic diet is explained. ${ }^{6}$ This discussion includes in-depth analysis of expected benefits, possible risks, and potential dangers of 
Table 1 Ketogenic counseling: the 5R model

\begin{tabular}{|l|}
\hline Rapport \\
\hline With health care team \\
\hline With self (self-realization) \\
\hline Readiness to change \\
\hline Benefit-cost ratio \\
\hline Major life events (job/family stress, concurrent illness) \\
\hline Realistic realization \\
\hline Responsibilities and rights \\
\hline Resolve and resources \\
\hline Reliability \\
\hline Keto-literacy \\
\hline Rebounding from relapse \\
\hline Relationship \\
\hline With food \\
\hline With family/society \\
\hline
\end{tabular}

the intervention. Such an interview, conducted in a nonjudgmental and nonpaternalistic manner, allows the person to assess her/his risk-benefit ratio. Counseling also includes a description of an individual's rights and responsibilities following a ketogenic diet. Rights include, for example, the right to contact a health care team member for information or assistance when required. Responsibilities include self-management and creation/maintenance of resources required to practice effective self-management.

\section{Reliability}

Readiness to change must be accompanied by reliability in managing change. This is ensured during predietary counseling, and afterward as well, by imparting education in the nutritional, dietary, and culinary aspects of ketogenic diet. Prior to starting the diet, the person should be aware of how to identify and source keto-friendly food, read nutritional labels, prepare healthy meals, measure protein sizes, and plan a satisfactory menu. Keto-literacy also covers issues such as dining out and troubleshooting. Troubleshooting may be required when one is faced with unfamiliar food choices or when one relapses into a carbohydrate-rich diet. Although such relapses are sound to occur, it is important that the individual be conditioned psychologically to rebound from these (temporary) setbacks.

\section{Readiness to Change}

Predietary counseling is a theranostic (therapeutic + diagnostic) intervention. It aims not only to assess readiness to change dietary behavior but also to motivate the person to change. Thus, it serves a dual purpose. Readiness to change can be measured by assessing the resolve or firmness of the person understanding barriers such as stressful life events (e.g., family, job, concurrent illness), and by enquiring about the resources available to her or him. This helps assess if this is the right time for change.
Table 2 Counseling in a nutshell

\begin{tabular}{|l|}
\hline Biomedical issues \\
\hline Benefit-cost ratio \\
\hline Responsibilities and rights \\
\hline Keto-literacy \\
\hline Psychological issues \\
\hline $\begin{array}{l}\text { With self (self-realization) and resolve (rebounding } \\
\text { from relapse) }\end{array}$ \\
\hline Stress from life events (family, job, concurrent illness) \\
\hline With food \\
\hline Social issues \\
\hline With health care team \\
\hline Resources \\
\hline With family/society \\
\hline
\end{tabular}

The resolve to change is a dynamic concept and can be modified by an empathic explanation of the benefits of ketogenic diet. Other ways of building resolve are to foster peer motivation by people and families who have successfully managed a keto-diet and to provide counsel on stress management techniques and coping mechanisms.

Resource analysis includes enquiry regarding the availability, accessibility, affordability, and appropriateness of keto-friendly foods. Ability and willingness of family members to cook and serve keto-friendly meals is also a part of keto-resourcing.

\section{Relationship}

Apart from the biomedical assessment and counseling, one must explore the psychosocial basis of obesity as well. This involves interviewing to understand the individual's relationship with food, including drivers for eating and drinking. This discussion will automatically evolve into an exploration of the relationship of food with family and society. The importance of food and specific foods in social interactions with the family and larger society must be considered. These insights will help identify potential obstacles to successful maintenance of ketogenic diet and suggest preemptive step to overcome them.

\section{Summary}

The 5R model provides a simple, yet comprehensive, coverage of the essential components of predietary counseling. It is an essential learning tool for all health care professionals who deal with ketogenic diet.

\section{Conflict of Interest}

None.

\section{References}

1 Gupta L, Khandelwal D, Kalra S, Gupta P, Dutta D, Aggarwal S. Ketogenic diet in endocrine disorders: current perspectives. J Postgrad Med 2017;63(4):242-251 
74 Predietary Counseling in Ketogenic Diet: The 5R Model Rosha et al.

2 Forouhi NG, Misra A, Mohan V, Taylor R, Yancy W. Dietary and nutritional approaches for prevention and management of type 2 diabetes. BMJ 2018;361:k2234

3 Azar ST, Beydoun HM, Albadri MR. Benefits of ketogenic diet for management of type two diabetes: a review. Journal of Obesity and Eating Disorders 2016;2(2)
4 Engel GL. The clinical application of the biopsychosocial model. Am J Psychiatry 1980;137(5):535-544

5 Kalra S, Baruah MP, Unnikrishnan AG. Responsible patientcentered care. Indian J Endocrinol Metab 2017;21(3):365-366

6 Tips and advice. Available at: https://www.noviquehealth. com/blog/category/tips/. Accessed July 30, 2018 